\title{
Soybean Resistance Locus Rhg1 Confers Resistance to Multiple Cyst Nematodes in Diverse Plant Species
}

\author{
Katelyn J. Butler, ${ }^{1,2}$ Shiyan Chen, ${ }^{3}$ John M. Smith, ${ }^{1}$ Xiaohong Wang, ${ }^{4,5}$ and Andrew F. Bent ${ }^{1, \dagger}$ \\ ${ }^{1}$ Department of Plant Pathology, University of Wisconsin-Madison, Madison, WI 53706 \\ 2 Department of Biology, Anderson University, Anderson, IN 46012 \\ ${ }^{3}$ Plant Pathology and Plant-Microbe Biology Section, School of Integrative Plant Science, Cornell University, Ithaca, NY 14853 \\ ${ }^{4}$ Robert W. Holley Center for Agriculture and Health, U.S. Department of Agriculture-Agricultural Research Service, Ithaca, NY 14853 \\ ${ }^{5}$ Plant-Microbe Biology Section, School of Integrative Plant Science, Cornell University, Ithaca, NY 14853 \\ Accepted for publication 23 July 2019.
}

\begin{abstract}
Cyst nematodes consistently threaten agricultural production, causing billions of dollars in losses globally. The Rhgl (resistance to Heterodera glycines 1) locus of soybean (Glycine max) is the most popular resistance source used against soybean cyst nematodes (H. glycines). Rhgl is a complex locus that has multiple repeats of an $\approx 30$-kilobase segment carrying three genes that contribute to resistance. We investigated whether soybean Rhgl could function in different plant families, conferring resistance to their respective cyst nematode parasites. Transgenic Arabidopsis thaliana and potato (Solanum tuberosum) plants expressing the three soybean Rhgl genes were generated. The recipient Brassicaceae and Solanaceae plant species exhibited elevated resistance to $H$. schachtii and Globodera rostochiensis and to $G$. pallida, respectively. However, some negative consequences

encodes a toxic version of an alpha-SNAP protein that has been demonstrated to interfere with vesicle trafficking. Using a transient expression assay for Nicotiana benthamiana, native Arabidopsis and potato alpha-SNAPs (soluble NSF [ $N$-ethylamine sensitive factor] attachment protein) were found to compensate for the toxicity of soybean Rhgl alpha-SNAP proteins. Hence, future manipulation of the balance between Rhgl alpha-SNAP and the endogenous wild-type alpha-SNAPs (as well as the recently discovered soybean NSFRAN07) may mitigate impacts of Rhgl on plant productivity. The multispecies efficacy of soybean Rhgl demonstrates that the encoded mechanisms can function across plant and cyst nematode species and offers a possible avenue for engineered resistance in diverse crop species.
\end{abstract} including reduced root growth and tuber biomass were observed upon Rhgl expression in heterologous species. One of the genes at Rhgl
Keywords: genetics and resistance, nematology
Cyst nematodes in the Heteroderinae subfamily consistently threaten agricultural production and annually cause substantial crop losses (Nicol et al. 2011). Cyst nematodes dramatically reprogram certain host root cells to form a syncytium, a feeding structure characterized by fusion of adjacent root cells to form a large multinucleate cell with dense cytoplasm and substantially smaller vacuoles (Endo 1964; Kyndt et al. 2013).

Most major crops have co-adapted species of cyst nematodes that can limit production; in a number of cropping systems, cyst nematodes are considered one of the most threatening pathogens (Turner and Rowe 2006). For example, the soybean cyst nematode (SCN; Heterodera glycines) is the most yieldreducing pathogen of soybean, and it is now present in all major soybean-producing areas in the United States (Allen et al. 2017; Niblack 2005). Potato cyst nematodes (PCN; Globodera rostochiensis and G. pallida) are a similarly major issue in potato production in Europe and South America, where the pathogen originated (Plantard et al. 2008). As a

†Corresponding author: A. Bent; afbent@wisc.edu

Funding: This work was supported by funding to A. F. Bent from the United States Department of Agriculture-National Institute of Food and Agriculture-Agriculture and Food Research Initiative Award number 2014-67013-21775, the Wisconsin Experiment Station Hatch program, and the Wisconsin Soybean Marketing Board.

*The $e$-Xtra logo stands for "electronic extra" and indicates that eight supplementary figures are published online.

A patent application covering the presently described work has been filed by the Wisconsin Alumni Research Foundation.

(C) 2019 The American Phytopathological Society worldwide-recognized quarantine pest, $\mathrm{PCN}$ can infect several Solanaceous crops, including potato, tomato, and eggplant, and it can cause significant yield losses if proactive disease management practices are not utilized (Evans and Rowe 1998; Turner and Rowe 2006). Beet cyst nematode (BCN; $H$. schachtii) is an ongoing issue in sugar beet production that can also infect cruciferous vegetables such as cabbage (Evans and Rowe 1998). Additionally, BCN can infect Arabidopsis thaliana, which has made it a widely adopted model of cyst nematode species for studies of interactions between plants and nematodes (Siddique and Grundler 2015; Sijmons et al. 1991).

Cyst nematodes are particularly difficult to manage because of their long persistence as unhatched eggs encased in cysts in the soil, as well as their resistance to chemical treatments. Quarantine, crop rotation, and host resistance are the primary means of control for cyst nematodes, with resistance being the most economically and environmentally favored practice (Turner and Rowe 2006). Accordingly, plant genes for resistance to cyst nematodes are valuable traits in crop breeding, and significant efforts have been expended to identify resistance to the major cyst nematode pests. Resistance to G. rostochiensis pathotypes Ro1 and Ro4 is available from the $H 1$ resistance gene, which has been widely introgressed into many commercial potato cultivars (Brodie and Mai 1989; Finkers-Tomczak et al. 2011). However, other G. rostochiensis pathotypes and $G$. pallida can reproduce on potato cultivars containing the $H 1$ gene. Additionally, there is no gene or single locus that confers complete resistance to G. pallida (Gebhardt 2013; Minnis et al. 2002). Resistance to BCN in sugar beet is an important trait for beet growers. Several sources of strong resistance were identified in wild beet species; however, integration of these traits 
into cultivated varieties has been troublesome (reviewed in Zhang et al. 2008). Traits have been introduced to create commercial varieties with resistance or tolerance to $\mathrm{BCN}$, but their performance has varied (Hauer et al. 2015). One major gene, Hs ${ }^{\text {pro-1 }}$, has been cloned and encodes a protein with leucine-rich repeats and a transmembrane domain associated with typical disease resistance proteins (Cai 1997).

The Rhgl (resistance to $H$. glycines 1) locus from soybean accession PI 88788 is the primary locus deployed for SCN management. This locus comprises a $\approx 30$-kb block with four genes tandemly repeated up to 10 times to comprise $\mathrm{a} \approx 300-\mathrm{kb}$ resistance locus (Cook et al. 2012; Lee et al. 2015). Three of the repeated genes contribute to full resistance in soybean (Cook et al. 2012). The three genes conferring resistance encode a putative amino acid transporter (Glyma.18G022400), an $\alpha$-SNAP (soluble NSF [N-ethylmaleimide sensitive fusion]-associated protein; Glyma.18G022500), and a protein with minimal annotation other than a putative wound-inducible domain (Glyma.18G022700) (Cook et al. 2012). The mechanisms through which the transporter and wound-inducible protein contribute to resistance remain unclear (Guo et al. 2019), but the function of the $\alpha$-SNAP has been, at least partially, elucidated. The $\alpha$-SNAP proteins usually are highly conserved housekeeping proteins required for cellular vesicular trafficking. However, the $\alpha$-SNAPs encoded by the resistance-conferring Rhgl loci $\left(\alpha-\mathrm{SNAP}_{R h g l}\right)$ have amino acid polymorphisms at otherwise highly conserved residues, causing interference with proper vesicular trafficking (Bayless et al. 2016; Cook et al. 2014). These aberrant $\alpha$-SNAP Rhgl $_{\text {p }}$ proteins were found to accumulate to high levels in developing syncytia. It is thought that high levels of toxic $\alpha-$ SNAP $_{R h g l}$ interfere with vesicular trafficking and block nematode development by interfering with syncytium health (Bayless et al. 2016).

Knowledge to date regarding Rhgl suggests that the locus represents an unusual evolutionary event that evolved to directly interfere with conserved mechanisms required for cyst nematode parasitism, rather than encoding a protein that recognizes specific nematode pathogens and activates host defenses (Bayless et al. 2016; Cook et al. 2012, 2014; Liu et al. 2017). In the present study, we tested the hypothesis that Rhgl efficacy can be extended beyond $\mathrm{SCN}$ to function in other plant families against other cyst nematode species or genera. Transgenic Arabidopsis and potato expressing Rhgl were generated and challenged with $\mathrm{BCN}$ and PCNs, respectively. Excitingly, Rhgl was found to confer resistance in these diverse plant families against their respective cyst nematode parasites. We also completed initial studies regarding the potential consequences of expressing a foreign and toxic $\alpha-\mathrm{SNAP}_{\text {Rhgl }}$ protein in these plant species. Some negative consequences of Rhgl expression in Arabidopsis and potato such as reduced root growth and tuber biomass were observed. In separate experiments, the strong toxicity of $\alpha-\mathrm{SNAP}_{R h g l}$ in Nicotiana benthamiana was found to be rescued by endogenous potato and Arabidopsis $\alpha$-SNAP proteins. The PI 88788-derived haplotype of $R h g l$ has been used for soybean for decades without yield penalties, suggesting the presence of additional factors in the soybean genome that allow Rhgl-containing soybeans to thrive (Bayless et al. 2018). The present results demonstrate that Rhgl can function in other plant species and confer resistance against different cyst nematode species, thus providing a tool to further investigate both nematode virulence and novel host resistance. Our findings also support a proposed method for the development of engineered nematode resistance in crops where resistance is rare or ineffective.

\section{MATERIALS AND METHODS}

Oligonucleotides. The oligonucleotide primer sequences used in this study are listed in Supplementary Figure S8.

Generation of $\boldsymbol{R h g} \mathbf{l}$ gene constructs. A. thaliana ecotype Col-0 (Columbia) was transformed with three-gene Rhgl overexpression constructs used previously by Cook et al. (2012). Briefly, coding sequences for each of the three genes were cloned into binary vector pSM101 (Melito et al. 2010). Both Glyma.18G022500 and Glyma.18G022700 were expressed under a soybean ubiquitin promoter (Hernandez-Garcia et al. 2010), and Glyma.18G022400 was expressed under the nos promoter. A $3 \times-$ HA tag was added to the C-terminus of Glyma.18G022500 and Glyma.18G022700, and a $4 \times$ myc tag was added to the C-terminus of Glyma.18G022400 (Cook et al. 2012). For transformation of Solanum tuberosum 'Désirée', the binary vector pCambia2300 was PCR-amplified with Kapa HiFi polymerase (Kapa Biosystems, California) to add MluI and PspOMI restriction sites to the multicloning site using the polymerase incomplete primer extension (PIPE) method (Klock and Lesley 2009). In the potato overexpression plasmid, the aforementioned expression cassette contained epitope-tagged cDNAs of the three Rhgl genes Glyma.18G022400, Glyma.18G022500, and Glyma.18G022700; however, the HA tag was shifted to the N-terminus of Glyma.18g022500. The cassette was PCR-amplified with Kapa $\mathrm{HiFi}$ Polymerase to contain AvrII restriction overhangs, digested, and then ligated into the $X b a \mathrm{I}$ restriction site of pCambia2300 using T4 DNA ligase (Promega, Madison) to create plasmid pC23Rhg1-OXCNC. For the pCambia2300 native genomic three-gene Rhgl construct, a native genomic region of the Glyma. $18 \mathrm{G022700}$ gene $\left(3.66 \mathrm{~kb}\right.$ total, including $1.8 \mathrm{~kb}$ upstream of $5^{\prime}$ UTR and $1.0 \mathrm{~kb}$ downstream of $\left.3^{\prime} \mathrm{UTR}\right)$ was amplified from fosmid subclones of Rhgl derived from PI 88788 (Fosmid-32) (Cook et al. 2012) and blunt-cloned into the pTopo XL vector to make pTopo XL 2610 native by following the manufacturer's instructions (Invitrogen). Similarly, an 11.21-kb region containing the divergently transcribed Glyma.18G022400 and Glyma.18G022500 genes (including $1.5 \mathrm{~kb}$ downstream of $24003^{\prime}$ UTR and $0.8 \mathrm{~kb}$ downstream of the $25003^{\prime}$ UTR) was amplified from Fosmid-32, with $S b f \mathrm{I}$ and AvrII restriction sites incorporated at the 5' and 3' ends, and blunt-cloned into a pTopo XL vector. This pTopo XL 2580-2590 native vector was then digested with SbfI and AvrII, gel-purified, and ligated into the pTopo XL 2610 native vector, which was digested with $P s t \mathrm{I}-X b a \mathrm{I}$, thereby generating pTopo XL 2580-2590-2610 with the three native Rhgl genes. The combined pTopo XL 2580-2590-2610 native genomic fragment was digested using NotI and MluI sites present in the pTopo XL vector, gel-purified, and ligated into pCambia2300 MluIPspOMI vector cut with NotI and PspOMI, thereby generating pC23Rhg1-N. The combined total native genomic region of $\mathrm{pC} 23-$ Rhg $1-\mathrm{N}$ is $\approx 14.9 \mathrm{~kb}$.

Generation of transgenic potato. Transgenic potato lines expressing the three Rhgl genes under the control of their native soybean promoters or the overexpression cassette already described were generated as previously described (Chronis et al. 2014a). Briefly, potato internode segments from in vitro-grown plants (Solanum tuberosum 'Désirée') were cut, incubated in a cell suspension of Agrobacterium tumefaciens strain LBA4404 containing the specified binary plasmid, and transferred onto callus and shoot induction medium. After $\approx 4$ weeks, emerging shoots were dissected and transferred to culture tubes containing propagation medium. Plantlets were cultivated in a growth chamber at $24^{\circ} \mathrm{C}$ under a $16 \mathrm{~h} \mathrm{light} / 8 \mathrm{~h}$ dark cycle. To confirm transgene expression in independent transgenic lines, mRNA was isolated from plant roots using a Dynabeads mRNA DIRECT Kit (Life Technologies, Carlsbad, CA). DNA contamination was removed by treatment with DNase I (Life Technologies). First-strand cDNA was synthetized from $50 \mathrm{ng}$ of mRNA using ProtoScript II reverse transcription (NEB, Ipswich, MA). Primers specific to Glyma.18G022400 of Rhg1 (Rhg1_F and Rhg1_R) were used for PCR detection of gene expression. The StUbi gene (XM_ 010326024.1) was used as an internal reference in the PCR assay. The PCR cycling conditions were $94^{\circ} \mathrm{C}$ for $40 \mathrm{~s}$, followed by 25 cycles (for the StUbi gene) or 30 cycles (for the Rhg 1 gene) of $94^{\circ} \mathrm{C}$ 
for $40 \mathrm{~s}, 60^{\circ} \mathrm{C}$ for $40 \mathrm{~s}, 72^{\circ} \mathrm{C}$ for $1 \mathrm{~min}$, and a final reaction of $72^{\circ} \mathrm{C}$ for $10 \mathrm{~min}$.

Generation of transgenic Arabidopsis. A. thaliana accession Columbia (Col-0) plants were transformed by the floral dip method (Clough and Bent 1998), and transgenic T1 seedlings were selected on $1 / 2 \times$ MS plates containing $25 \mu \mathrm{g} / \mathrm{ml}$ hygromycin. Transgenic T2 seedlings were identified by germination on the aforementioned media prior to use. Homozygous transgenic T3 lines were established by single-seed descent from $\mathrm{T} 2$ plants and testing for uniform germination of the progeny family on the aforementioned media.

Quantitative PCR to determine the copy number of the Arabidopsis transgene. Genomic DNA of Arabidopsis seedlings was extracted using a MoBio Power Plant DNA Extraction kit including RNase treatment (MoBio, St. Louis, MO). Six seedlings were pooled per replicate, and three replicates were run in parallel. Quantitative PCR (qPCR) was performed for $10 \mathrm{ng}$ genomic DNA with Bullseye Evagreen $2 \times$ Supermix (MidSci, St. Louis, MO) using a CFX96 real-time PCR detection system (Bio-Rad, Hercules, $\mathrm{CA}$ ) and the manufacturer-suggested Bullseye Evagreen cycling parameters. Each sample had two technical replications and each primer set had a no template control, which displayed no amplification. Known single-copy Arabidopsis genes At4g03280 and At1g06570 were used as the reference and calibrator gene, respectively. Primers specific to the Rhgl gene Glyma.18G022400 were used to determine the copy number of the Rhgl transgene. All primers were validated with efficiency curves. Amplification was normalized to At4g0380, and Glyma.18G022400 amplification was normalized to the calibrator At1g06570. The copy number was calculated using the $\Delta \Delta \mathrm{Cq}$ method (Livak and Schmittgen 2001).

Reverse-transcription PCR of Arabidopsis to detect the expression of $\boldsymbol{R h g l}$ genes. Total RNA was extracted from a pooled group of 10 Arabidopsis seedlings that were 10 days old and grown under $12 \mathrm{~h}$ days at $22^{\circ} \mathrm{C}$ on $1 / 2 \times \mathrm{MS}$ and then flash-frozen in liquid nitrogen. RNA was extracted with the Direct-zol RNA extraction kit with on-column DNase treatment (Zymo Research, Irvine, CA) and analyzed for quality on a $1.5 \%$ agarose gel stained with ethidium bromide. cDNA was synthesized from $1000 \mathrm{ng}$ of RNA with the iScript cDNA synthesis kit (Bio-Rad), and the 20- $\mu$ l reaction was diluted to $100 \mu \mathrm{l} ; 3 \mu \mathrm{l}$ of cDNA was used per reversetranscription PCR (RT-PCR) with the gene-specific primers for the Rhgl transgene. The Arabidopsis gene At3g18780 (ACT2) was used as a positive control. Amplification reactions were performed with DNA polymerase (Ampliqon, Odense, Denmark). The PCR cycling conditions were $95^{\circ} \mathrm{C}$ for $2 \mathrm{~min}$, followed by 30 cycles of $95^{\circ} \mathrm{C}$ for $30 \mathrm{~s}, 54^{\circ} \mathrm{C}$ for $30 \mathrm{~s}$, and $72^{\circ} \mathrm{C}$ for $45 \mathrm{~s}$, and then a final extension step at $72^{\circ} \mathrm{C}$ for $5 \mathrm{~min}$. Then, $5 \mu \mathrm{l}$ of each reaction was analyzed on a $1 \%$ agarose gel stained with ethidium bromide.

Defense gene analysis. To test for constitutive defense gene expression, seedlings were grown on $1 / 2 \times$ MS without sucrose for $16 \mathrm{~h}$ /day at $24^{\circ} \mathrm{C}$. Ten-day-old seedlings were sprayed with $1 \mathrm{mM}$ salicylic acid (Sigma-Aldrich) or water as a control. For jasmonic acid-induced defenses, 14-day-old seedlings were grown in $1 / 2 \times$ MS and $2 \%$ sucrose and treated with $100 \mu \mathrm{M}$ methyl-jasmonate (Sigma-Aldrich) or water as control. Twenty-four hours after treatment, seedling leaf tissues from approximately three to five seedlings were pooled and flash-frozen in liquid nitrogen. RNA extraction and cDNA synthesis were performed as described. RTPCR was performed with GoTaq DNA polymerase (Promega, Madison, WI) with gene-specific primers. The PCR cycling conditions were $95^{\circ} \mathrm{C}$ for $2 \mathrm{~min}$, followed by 25 cycles of $95^{\circ} \mathrm{C}$ for $30 \mathrm{~s}, 48^{\circ} \mathrm{C}$ for $30 \mathrm{~s}$, and $72^{\circ} \mathrm{C}$ for $30 \mathrm{~s}$, and then a final extension step of $72^{\circ} \mathrm{C}$ for $5 \mathrm{~min}$. An equal amount of each reaction was analyzed on a $1 \%$ agarose gel stained with ethidium bromide.

Immunoblots for Rhg1 protein detection. To detect Rhg1 protein levels in Arabidopsis, root tissue was collected from 1-month-old seedlings grown on $1 / 2 \times$ MS media and immediately frozen in liquid nitrogen. Frozen samples were homogenized using a PowerLyzer 24 (MO BIO, Carlsbad, CA) for one cycle at $30 \mathrm{~s}$, flash-frozen, and homogenized again in $50 \mathrm{mM}$ Tris- $\mathrm{HCl}(\mathrm{pH} 6.5)$, $100 \mathrm{mM} \mathrm{NaCl}, 5 \mathrm{mM}$ EDTA, $0.2 \%$ Triton X-100, and 10\% (vol/vol) glycerol during an additional cycle of $30 \mathrm{~s}$. After protein separation by SDS-PAGE and blotting, immunoblots were incubated overnight at $4^{\circ} \mathrm{C}$ with an antibody that detects myc tags (Sigma-Aldrich, St. Louis, MO) or a conjugated antibody that detects HA tags (Sigma-Aldrich) at $1: 5,000$ or $1: 10,000$, respectively, in 5\% nonfat dry milk TBS-T (50 mM Tris, $150 \mathrm{mM}$ $\mathrm{NaCl}, 0.05 \%$ Tween 20). Secondary horseradish peroxidaseconjugated goat antirabbit IgG was added at 1:10,000 to myc blots and incubated for $1 \mathrm{~h}$ at room temperature, followed by five washes of TBS-T. Detection was performed with Supersignal West Pico or Dura chemiluminescent substrate (Thermo Scientific, Waltham, MA) and developed using a ChemiDoc MP chemiluminescent imager (Bio-Rad). Similar protocols were used with potato root tissue to detect Rhg1 proteins.

For cell fraction work, infected potato root tissue was ground on ice using a mortar and pestle, and cytosolic and microsomal fractions were isolated as described previously (Zhang and Peck 2011). Immunoblots were performed and imaged as described. An MPK6 antibody (Agrisera, Vännäs Sweeden AS12 2633) was used as a cytosolic marker, and calnexin antibody (Agrisera, Vännäs Sweeden AS12 2365) was used as a microsomal marker.

Potato PCN assays. G. rostochiensis (pathotype Ro1) or G. pallida (pathotype $\mathrm{Pa} 2 / 3$ ) $\mathrm{PCN}$ was propagated and hatched as previously described (Chronis et al. 2014b; Lu et al. 2008). Rhgl transgenic plantlets were planted in six-well plates with propagation medium containing timentin $(100 \mu \mathrm{g} / \mathrm{ml})$. Plants were grown at $24^{\circ} \mathrm{C}$ under 16 -h light/8-h dark conditions for 14 days. Approximately 300 freshly hatched and surface-sterilized second-stage juveniles (J2) were inoculated on each plantlet as described by Chronis et al. (2014b). Twelve seedlings were included for each transgenic line. Six weeks after nematode inoculation, the number of nematode females formed on plant roots was counted under a dissecting microscope (Carl Zeiss Discovery V8). Data were analyzed by analysis of variance (ANOVA) using $\mathrm{R}$ software ( $\mathrm{R}$ Core Team).

Arabidopsis BCN infection assay. $H$. schachtii were propagated on collard greens and harvested using sucrose gradient centrifugation. Cysts were stored in sand at $4^{\circ} \mathrm{C}$ prior to use. To obtain infective $\mathrm{J} 2 \mathrm{~s}$, cysts were crushed and eggs were collected and hatched as described by (Cook et al. 2012). Prior to hatching, eggs were surface-sterilized by treatment with $0.02 \%$ sodium azide for $20 \mathrm{~min}$ and rinsing with deionized water for $3 \mathrm{~min}$. Approximately 5 days after hatching, infective $\mathrm{J} 2$ s were surfacesterilized using $\mathrm{HgCl}_{2}$ as described by (Cook et al. 2012). Arabidopsis seeds were surface-sterilized by vortexing for $2 \mathrm{~min}$ in $95 \%$ ethanol and allowed to air-dry in a laminar flow sterile hood before plating. Individual seeds were plated in sterile 12well plates filled with $4 \mathrm{ml}$ of modified Knop's media (Sijmons et al. 1991) supplemented with $2 \%$ sucrose. Each seed was randomly assigned to a numbered well to blind the investigator during subsequent nematode counting. Plates were wrapped with micropore tape and placed in the dark at $4{ }^{\circ} \mathrm{C}$ for 3 days before being submitted to $22^{\circ} \mathrm{C}$ for 16 -h/day. Twelve-day-old seedlings were inoculated with 100 to 200 sterile $H$. schachtii J2s at the base of the plant. Inoculated seedlings were placed in the dark at $28^{\circ} \mathrm{C}$ for 25 days before females on the roots were counted. Three independent experiments were performed. Data were analyzed by an ANOVA (genotype and experiment) using R (R Core Team).

Arabidopsis root knot nematode infection assay. Meloidogyne incognita root knot nematodes were propagated and hatched as described previously (Jaouannet et al. 2013). Seeds of Arabidopsis ecotype Col-0 and transgenic Col-0 lines expressing Rhgl genes were surface-sterilized and planted in six-well plates containing $0.5 \times \mathrm{MS}$ medium, $2 \%$ sucrose, and $0.8 \%$ agar. Plants were grown at $24^{\circ} \mathrm{C}$ under 16 -h light/8-h dark conditions for 
2 weeks. Approximately 300 freshly hatched and surface-sterilized juveniles (J2) were then inoculated on each seedling as described by Hamamouch et al. (2012). Galls formed on roots were counted under a microscope 4 weeks after inoculation.

Phenotypic analysis of $\mathrm{Rhgl}^{+}$potato plants. Potato seedlings from in vitro tissue culture were transplanted into 2gallon pots, and plants were grown in a greenhouse at 22 to $28^{\circ} \mathrm{C}$ with a 16-h light/8-h dark cycle for 4 months. Five replicates of each transgenic line were included. Tubers from each line were collected and weighed at the end of plant growth, and data were analyzed by an ANOVA using R software (R Core Team).

Arabidopsis root length assay. Arabidopsis seeds were surface-sterilized in the same manner used for the $\mathrm{BCN}$ infection assays. Seeds were plated by genotype on $1 / 2 \times$ Murashige and Skoog medium with $1 \times$ B5 vitamins, $1 \%$ sucrose, and $0.5 \%$ agar. Plated seeds were covered with an additional layer of the same media and vernalized in the dark at $4^{\circ} \mathrm{C}$ for 3 days. Plates were then moved to a growth chamber $\left(22^{\circ} \mathrm{C}, 16\right.$-h light/8-h dark cycle $)$ and placed on edge at a $90^{\circ}$ angle. After 4 days, the length of the root was marked and plates were shifted to $60^{\circ}$ angles. Four days later, the final root length was marked and growth was measured between these two points by capturing seedling images and measuring root growth with the NeuronJ plugin (Fridman et al. 2014; Meijering et al. 2004) for ImageJ (NIH). This experiment was repeated three separate times. Statistical analysis by an ANOVA was performed using R (R Core Team).

Arabidopsis nematode penetration assay. To measure nematode penetration, 10-day-old seedlings were inoculated with $50 \mathrm{H}$. schachtii $\mathrm{J} 2$ nematodes. Plants were stained $48 \mathrm{~h}$ after infection (Bybd et al. 1983), and the number of nematodes penetrated per root was determined using an Olympus DP73 microscope. Penetration data were analyzed by an ANOVA using $\mathrm{R}$ software (R Core Team).

Generation of plasmids for transient protein expression. Vectors for transient overexpression of Arabidopsis and potato $\alpha$-SNAPs were constructed using the pSM101 binary vector (Melito et al. 2010). Coding sequences for Arabidopsis $\alpha$-SNAP At03g56190.1 and potato $\alpha$-SNAP Sotub06g011010.1.1 were amplified from the plant genotypes Col-0 and Désireé, respectively, used for transformation. RNA was extracted from plant tissues using a Direct-Zol RNA extraction kit with on-column DNase treatment (Zymo Research, Irvine, CA) and analyzed for quality by gel electrophoresis on a $1.5 \%$ agarose gel. cDNA was synthesized with iScript cDNA Synthesis kit (Bio-Rad). $\alpha$-SNAP coding sequences were amplified from cDNA with KAPA HiFi Polymerase with specific primers (KAPA Biosystems, Wilmington, MA). Amplified ORFs were then placed between the soybean ubiquitin promoter (Hernandez-Garcia et al. 2010) and nos terminator in the vector pBluescript using Gibson assembly (Gibson et al. 2009) and sequence-verified. The overexpression cassettes were digested from pBluescript using XbaI/PstI, gel-extracted using the QIAquick Gel Extraction kit (Qiagen, Hilden, Germany), and ligated into the binary vector pSM101 using T4 DNA ligase (Promega, Madison, WI). Final constructs were transformed into Agrobacterium tumefaciens strain GV3101 (pMP90) using the freeze-thaw method.

Transient gene expression in Nicotiana benthamiana. Agrobacterium-mediated transient expression was performed as described by (Bayless et al. 2016). Within each experiment, two leaves on multiple plants were used for infiltration, and the infiltration location was randomized between leaves. Images were collected 8 to 9 days after infiltration using a Canon Rebel T3i and de-identified (masked to rater); then, each infiltrated area was rated using a standardized scale of 0 to 5 scale, with 0 indicating no visible signs of chlorosis or necrosis and 5 indicating complete death of the infiltrated tissues. Ratings from two independent experiments (for potato $\alpha$-SNAPs) or three independent experiments (for Arabidopsis $\alpha$-SNAPs) were analyzed using the pairwise Wilcoxon ranksum test in $\mathrm{R}$ ( $\mathrm{R}$ Core Team).

\section{RESULTS}

Transgenic potato lines expressing Rhgl proteins are more resistant to potato cyst nematodes. To determine the efficacy of Rhgl in other plant species, transgenic potato lines expressing the set of three resistance-associated genes of the Rhgl locus (Glyma.18g022400, Glyma.18g022500, and Glyma.18g022700) were generated. Four independent transgenic potato lines were chosen for further study. Two lines received the three Rhgl genes with added epitope tags and under the control of the following strong promoters: the Glycine max ubiquitin promoter for HA-Glyma.18g022500 and Glyma.18gO22700-HA and an Agrobacterium nos promoter for Glyma.18g022400-MYC. Two other transgenic potato lines received the three Rhgl genes surrounded by their native Rhgl promoter and terminator sequences. The four independent potato lines were selected for study after examining Glyma.18G022400 expression by RT-PCR (Supplementary Fig. S1, samples 10, 13, 2, and 9).

Transgenic potato lines were challenged with G. rostochiensis and Globodera pallida. All four Rhg $1^{+}$lines were found to be more resistant to both PCN species, as observed by significantly fewer females developing on $R h g 1^{+}$lines 6 weeks after inoculation (ANOVA, $P<0.01$ ) relative to the empty-vector control lines (Fig. 1). Relative resistance levels between the independent lines were similar for both PCN species. Results from independent experiments can be found in Supplementary Figure S2.

Subsequent studies confirmed expression of the three Rhg1 proteins in the transgenic potato lines that received epitope-tagged constructs (Supplementary Fig. S3). Proteins approximately matching the predicted sizes were first observed for Glyma.18G022400 and Glyma.18G022500. Although the Glyma.18G22700 protein was not detected in initial immunoblot experiments that detected the other two Rhg1 proteins, it was detectable using a refined immunoblot protocol with PCN-infected roots of constitutive expression $R h g l^{+}$lines in membrane fractionation experiments.

Arabidopsis lines expressing Rhg1 are resistant to H. schachtii. In Arabidopsis, the three Rhgl genes were overexpressed using epitope-tagged three-gene DNA constructs (all three genes on one Agrobacterium vector). Although the transformation rates were not recorded, Arabidopsis transformants were obtained at a lower-than-normal frequency for the Rhgl gene construct, suggesting possible toxicity of the Rhgl gene construct in Arabidopsis. Two independent Arabidopsis transgenic lines were used for nematode tests. They were subsequently determined to contain either one or $\approx 10$ copies of the transgenic Rhgl locus as determined by qPCR (copy number \pm SE: $0.92 \pm 0.09$ for line SI; $10.12 \pm 0.69$ for line MI; the parental Arabidopsis Col-0 line was confirmed to have an Rhgl copy number of zero). The single-copy and multi-copy Arabidopsis Rhgl+ lines were challenged with H. schachtii BCN. Arabidopsis plants expressing Rhgl were significantly more resistant to BCN, with fewer females developing on $R h g 1^{+}$lines relative to the wild-type Arabidopsis line (Fig. 2) (ANOVA, $P<0.001$ ). These results were further supported by comparisons with the performance of two Arabidopsis mutant lines for which altered resistance to $\mathrm{BCN}$ was previously reported. ETHYLENE INSENSITIVE 2-1 (ein2-1) and SALICYLIC ACID INDUCTION DEFICIENT 2-2 (sid2-2), which were previously demonstrated to have increased and decreased resistance, respectively (Wubben et al. 2001, 2008), also exhibited those phenotypes under our experimental conditions (Fig. 2). Results from individual experiments can be found in Supplementary Figure S4.

Semiquantitative RT-PCR and immunoblot results for tissue samples from Arabidopsis Rhg 1+ transgenic lines are shown in Supplementary Figure S5. Expression of all three Rhg 1 proteins was detected in the single copy insertion line. However, for the $\approx 10$ copy line, only the Glyma.18G22400 (amino acid permease) mRNA and protein were readily detectable. In the $\approx 10$-copy line, 
there was little or no detectable Glyma.18G22500 or Glyma.18G22700 mRNA or protein, consistent with silencing of those genes. The Glyma.18G22400 mRNA and protein appeared to be expressed at a higher level in the multi-copy line than the singlecopy line, consistent with the presence of multiple copies of Rhgl. Interestingly, the multi-copy Arabidopsis $R h g 1^{+}$line with primarily Glyma.18G22400 expression showed resistance to BCN, providing evidence that a high level of Glyma.18G22400 expression effectively conferred nematode resistance in this heterologous system.

Although not the primary focus of the present study, experiments to test the virulence of a $M$. incognita root knot nematode population were also performed using the aforementioned Arabidopsis singlecopy and multi-copy Rhgl+ lines. As shown in Supplementary

A

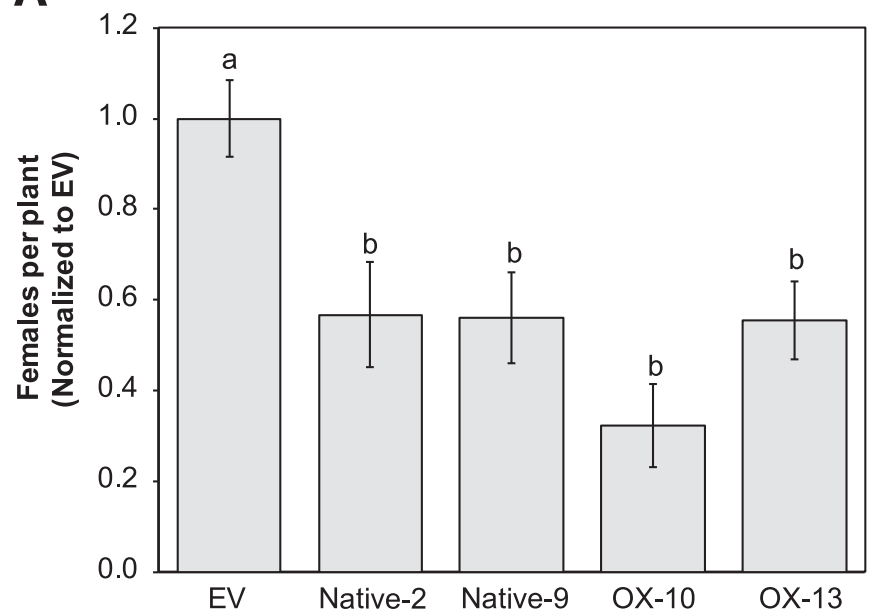

B

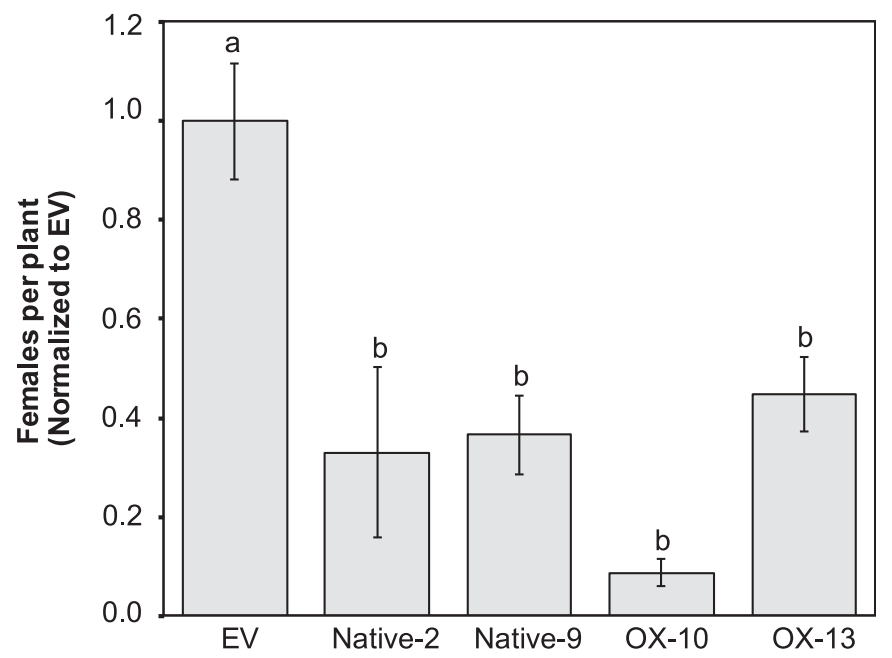

Fig. 1. Expression of Rhgl in potato confers resistance to potato cyst nematodes (Globodera rostochiensis and G. pallida). Relative susceptibility of transgenic Solanum tuberosum 'Désirée' lines to A, G. rostochiensis Ro1 and B, G. pallida $\mathrm{Pa} 2 / 3$ shown as the mean of nematode female numbers per plant normalized to the mean of female numbers per plant of the empty vector (EV) control line (EV: A, $n=20, \mathbf{B}, n=14$ ). Error bars display SEM. Means with different letters indicate statistically significant differences as determined by an analysis of variance (ANOVA) $(P<0.01)$. Within each of the three independent experiments (two for G. rostochiensis and one for G. pallida), the relative resistance of the transgenic lines with respect to each other were similar. Native-2 (A, $n=16, \mathbf{B}, n=3)$ and Native-9 (A, $n=15, \mathbf{B}, n=7)$ are two independent lines expressing the three Rhgl genes under the control of their native soybean promoters and terminators. OX-10 (A, $n=16, \mathbf{B}, n=5)$ and OX-13 (A, $n=14, \mathbf{B}, n=8)$ are independent lines expressing the three Rhgl genes under the control of constitutive plant promoters.
Figure S6, the single-copy line that expresses the three distinct soybean Rhgl proteins exhibited increased resistance to root knot nematodes, but no significantly increased resistance was observed for the multi-copy Rhg $1^{+}$Arabidopsis line (which, as presented, was found by protein immunoblot to be expressing a high level of only the Glyma.18G22400 protein product and low or undetectable amounts of the other two Rhgl-encoded protein products).

We also explored whether the observed Rhgl-mediated nematode resistance in Arabidopsis was likely to be the result of constitutively upregulated general defenses (Supplementary Fig. S7). RT-PCR was used to monitor the expression of $P R 1$, an established indicator of increased defenses associated with salicylic acid (SA) signaling (Garner et al. 2016). PRI was not expressed in untreated control or $R h g 1^{+}$plants. As a positive control, $P R l$ was found to be inducible in all three lines upon treatment with $1 \mathrm{mM}$ SA. Jasmonic acid-associated gene expression (Kammerhofer et al. 2015) was monitored using the established indicator gene $P D F 1.2$ (Garner et al. 2016). Low levels of PDF1.2 expression were observed in all lines, including the untreated wild-type control plants, possibly caused by growth in tissue culture plates, which were the context of the Arabidopsis BCN infection assays. Positive control treatment with $100 \mu \mathrm{M}$ methyl-jasmonate (mJA) induced expression of $P D F 1.2$ in all lines.

Heterologous expression of Rhgl impacts the growth of Arabidopsis roots but does not impact nematode penetration. Arabidopsis plants transformed with the Rhgl genes generated rosettes and roots that closely resembled nontransformed plants in their overall appearance. To more carefully test for impacts on root growth, the rate of root elongation was measured. Four days after germination on agar media in vertical petri dishes, the location of the root tip of growing seedlings was noted, and subsequent growth from this point was measured after another 4 days. Across three independent experiments, the $R h g 1^{+}$transgenic

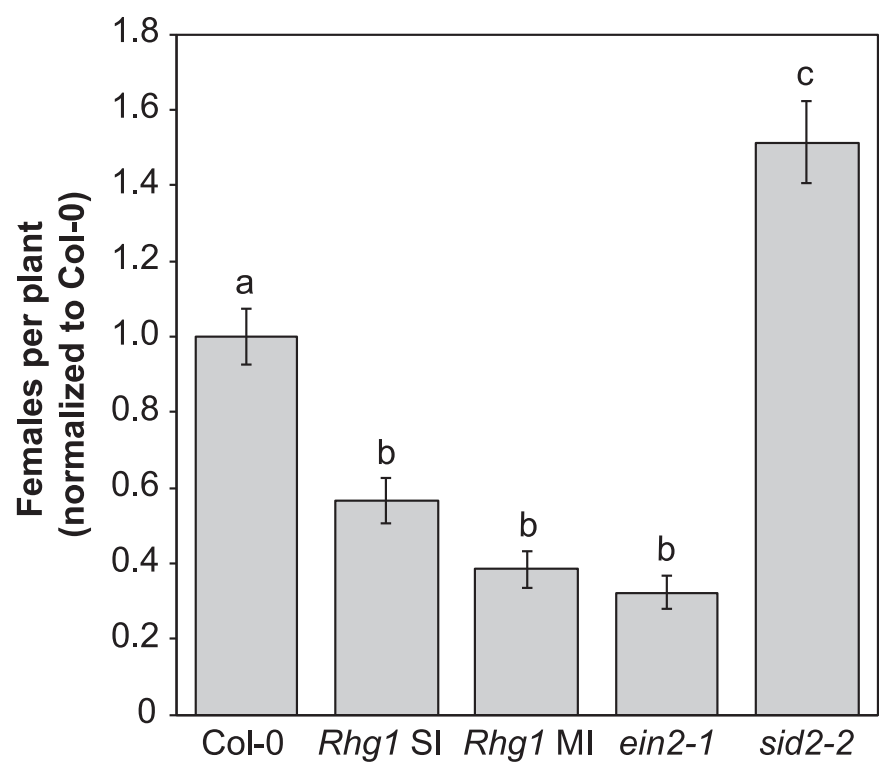

Fig. 2. Expression of Rhgl in Arabidopsis confers resistance to BCN. Susceptibility of transgenic and mutant Arabidopsis to Heterodera schachtii shown as mean cysts per plant 25 days after infection normalized to the mean for Col-0 controls within the same experiment. Data from three independent experiments are shown. Error bars display SEM. Letters indicate statistically significantly different means as determined by an analysis of variance (ANOVA) $(P<0.001)$. Col-0 (wild-type): total $n=64$; Rhg 1 SI (Col-0 with single transgenic insertion of the three Rhgl genes): $n=58$; Rhgl MI (Col-0 with multiple insertion of Rhg1 cassette): $n=57$; ein2-1 (ETHYLENE INSENSITIVE-2; mutant previously demonstrated to have increased resistance to H. schachtii): $n=52$; and sid2-2 (SALICYLIC ACID INDUCTION DEFICIENT-2; mutant previously demonstrated to have increased susceptibility to $H$. schachtii): $n=61$. 
lines exhibited a slight, but statistically significant, reduction in root growth (ANOVA, $P<0.05$ ) as compared with the wild-type plants (Fig. 3A). In a separate set of experiments, the rate of penetration of BCN J2 nematodes in Arabidopsis roots was determined. Despite the subtle but significant reduction in root growth, we did not detect an impact of Rhgl on $\mathrm{J} 2$ penetration of the Arabidopsis roots (Fig. 3B).

Transgenic potato expressing $R h g l$ have reduced tuber mass. To determine if overexpression of Rhgl has an effect on potato tuber growth and development, transgenic potato lines were grown to maturity in greenhouses, and the tuber weight of each plant was determined. When comparing the average total tuber production per plant for the transgenic lines to the empty vector (EV) control plants, both types of Rhgl overexpression lines exhibited a statistically significant reduction in tuber biomass (Fig. 4) (ANOVA, $P<0.1$ ). Although parameters such as the root elongation rate were not measured for potato, no overt macroscopic root
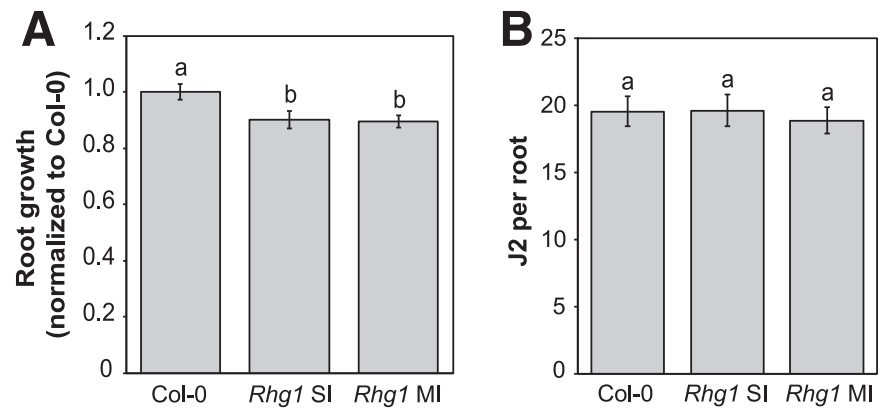

Fig. 3. Expression of Rhg1 reduces Arabidopsis root growth but does not affect BCN nematode penetration. A, Normalized mean Arabidopsis seedling tap root growth over 4 days. Error bars display SEM; letters indicate statistically significant differences as determined by an analysis of variance (ANOVA) $(P<0.05)$. Wild-type Arabidopsis Col-0 (Col-0): $n=87$; Rhgl SI (Col-0 with single transgenic insertion of the three Rhgl genes); $n=46$; and Rhgl MI (Col-0 with multiple insertion of Rhgl cassette): $n=70$. B, Mean \pm SEM for the number of $\mathrm{J} 2 \mathrm{BCN}$ penetrating Arabidopsis roots $48 \mathrm{~h}$ after inoculation. Col-0: $n=47$; Rhgl SI: $n=48$; and Rhg1 MI: $n=43$. According to the ANOVA, means are not significantly different $(P>0.1)$.

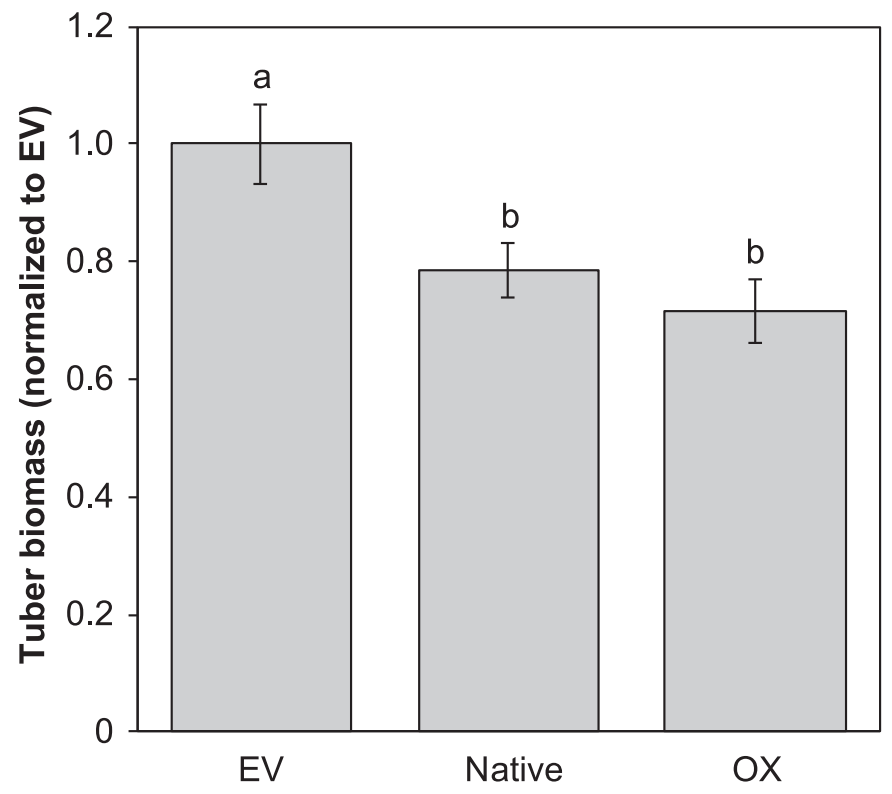

Fig. 4. Expression of Rhgl reduces tuber production of greenhouse-grown potatoes. Average tuber biomass per plant as measured by total tuber weight per plant of transgenic lines (native and OX) $(n=10)$ relative to that of the empty vector $(\mathrm{EV})(n=5)$ control lines is shown. Letters indicate statistically significant differences in the mean as determined by an analysis of variance (ANOVA) $(P<0.10)$. Error bars display SEM. phenotypes were observed for the $R h g 1^{+}$potato roots compared with the control roots.

Endogenous $\alpha$-SNAPS can compensate for toxicity of Rhg1 $\boldsymbol{\alpha}$-SNAPs. Our previous research revealed that one of the Rhgl genes, Glyma.18G22500, encodes an aberrant and toxic $\alpha$-SNAP $\left(\alpha-\right.$ SNAP $\left._{R h g l}\right)$ that apparently obstructs nematode development by interfering with vesicular trafficking in syncytia (Bayless et al. 2016; Cook et al. 2014). As such, overexpression of $\alpha-\mathrm{SNAP}_{R h g l}$ could have a negative effect on other plant species; a severe form of this effect has been confirmed when transiently expressing $\alpha-\mathrm{SNAP}_{R h g 1}$ in $N$. benthamiana leaves after Agrobacterium-mediated delivery (Bayless et al. 2016). Several previous studies have indicated that cell death evident in $N$. benthamiana at $\approx 4$ to 5 days after expression of $\alpha-\mathrm{SNAP}_{R h g 1}$ (or synthetic derivatives) is a result of the $\alpha$-SNAP $\mathrm{Sh}_{R l}$ impact on $\alpha$-SNAP/NSF/SNARE complexes and cellular vesicle trafficking (Bayless et al. 2016, 2018). The ancestrally polyploid soybean genome encodes $\alpha$-SNAPs at four loci, and the $\alpha$-SNAPs encoded at three of those loci (wild-type $\alpha$-SNAPs lacking the $\alpha$-SNAP Rhg $1_{1}$ amino acid polymorphisms) have been shown to exhibit dosedependent mitigation of the cytotoxicity caused by $\alpha-\mathrm{SNAP}_{R h g 1}$ (Bayless et al. 2016). Our success generating transgenic Rhgl+ Arabidopsis and potato lines in the present study suggested the presence of mechanisms in both Brassicaceae and Solanaceae that are able to modulate $\alpha-\mathrm{SNAP}_{R h g 1}$ toxicity. Therefore, we used the $N$. benthamiana expression assay to test the hypothesis that endogenous Arabidopsis and potato $\alpha$-SNAPs can, at least partially, rescue the cytotoxicity caused by $\alpha-\mathrm{SNAP}_{R h g 1}$.

For the $\alpha$-SNAP $\mathrm{Shgl}_{1}$ cytotoxicity assay, wild-type Arabidopsis and potato $\alpha$-SNAP genes were transiently co-expressed with $\alpha-S N A P_{R h g l}$ in $N$. benthamiana leaves. The genes encoding the proteins with the highest similarity to the soybean chromosome 18 wild-type $\alpha$-SNAP were selected out of two total from Arabidopsis and four total from potato. Arabidopsis At3g56190.1 encoding an $\alpha$-SNAP protein with $77.9 \%$ similarity to the soybean chromosome 18-encoded wild-type $\alpha$-SNAP was cloned downstream of a soybean ubiquitin promoter. As previously reported, the expression of soybean $\alpha-\mathrm{SNAP}_{R h g l}$ caused cell death and tissue collapse in the treated leaf sector (Fig. 5A). Co-expression of At3g56190.1 with $\alpha-S N A P_{R h g l}$ in $N$. benthamiana reduced the macroscopic chlorosis and necrosis indicative of $\alpha-\mathrm{SNAP}_{R h g l}$ cytotoxicity (Fig. 5A). Lesion severity scoring revealed a statistically significant reduction in cell death caused by $\alpha$-SNAP $\mathrm{Sh}_{\text {R } 1}$ when co-expressed with the Arabidopsis $\alpha$-SNAP (Fig. 5C) (Wilcoxon rank-sum test, $P<0.001$ ).

Potato Sotub06g011010.1 encoding an $\alpha$-SNAP protein with $76.5 \%$ similarity to the wild-type soybean chromosome 18-encoded $\alpha$-SNAP was also tested for its ability to compensate for $\alpha$ SNAP $_{R h g l}$ toxicity. The protein was co-expressed with

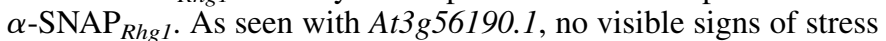
were observed even 8 to 9 days after infiltration at the infiltration sites where potato $\alpha-S N A P$ and $\alpha$-SNAP $P_{R h g l}$ were co-expressed (Fig. 5B), indicating that this potato $\alpha$-SNAP can rescue $\alpha$-SNAP Rhgl $_{1}$-induced cytotoxicity. Lesion severity scoring documented statistically significant reductions of $\alpha$-SNAP $\mathrm{Sh}_{R I}$-induced cell death upon co-expression of the potato $\alpha$-SNAP with the

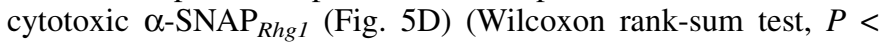
$0.001)$.

\section{DISCUSSION}

In the present study, we demonstrated the efficacy of the soybean cyst nematode resistance locus Rhgl in plants from two other taxonomic families compared to multiple cyst nematode species. The efficacy of Rhgl in Arabidopsis and potato suggested that Rhgl has evolved to interfere with one or more core or shared cyst nematode infection processes. Future work involving Rhgl could provide broadly applicable insight into cyst nematode parasitism as well as a novel form of host resistance. 
The transfer of the nematode resistance function across plant families has not been commonly observed. The movement of resistance has been reported across related plant species, such as the $\mathrm{CaMi}$ root knot nematode resistance gene from hot pepper that can confer root knot nematode resistance in tomato (Chen et al. 2007) and the $M i-1.2$ gene from tomato that conferred root knot nematode resistance in eggplant (Goggin et al. 2006). In those $M i-1.2$ experiments, the gene transfer remained within Solanaceae, but even that type of transfer is not always successful. Hero $A$ is a broadspectrum tomato resistance gene encoding a nucleotide-binding/ leucine-rich repeat (NLR) protein active against Globodera nematodes; however, when it was heterologously expressed in potato, it no longer conferred resistance (Sobczak et al. 2005). Our results confirmed the transfer of disease resistance when a cyst nematode resistance locus was moved from Fabaceae (soybean) into Solanaceae (potato) and Brassicaceae (Arabidopsis).

Previous research has shown that resistance conferred by some plant R genes that encode NLR proteins or pattern recognition receptors can be transferred across plant families (Boutrot and Zipfel 2017; Collinge et al. 2010; Narusaka et al. 2013). Less success has been observed in the transfer across plant families of other types of plant resistance traits with proven strong efficacy, with the notable exception of mlo, a loss-of-function mutation associated with powdery mildew resistance in a wide variety of plants (Kusch and Panstruga 2017). NB-LRR and pattern recognition receptor genes target specific pathogen effectors or microbial-associated molecular patterns (MAMPs); therefore, their functional range typically relies on the presence of pathogens that share a particular effector or effector target or a conserved pathogen marker. A resistance locus such as $R h g 1$, which does not encode a canonical receptor kinase or NLR protein, does not immediately imply pathogen detection as a mode of action. The capacity of Rhgl to function against both Heterodera and Globodera cyst nematodes suggested activity against one or more broadly conserved nematode infection strategies or modes of action. Elements of pathogen strain specificity of resistance remain because widespread use of Rhgl in soybean has led to the gradual development of SCN populations that partially overcome Rhgl-mediated resistance (McCarville et al. 2017), and virulence on different Rhgl-resistant sources appears to be unique for each source (Gardner et al. 2017). However, our results still suggest a broad resistance mechanism encoded at $R h g l$ that targets one or more infection processes that are conserved across diverse cyst nematode genera.

No constitutive expression of the plant defense indicator gene PRl was observed in the tested Rhgl+ Arabidopsis lines. A background level of $P D F 1.2$ expression was observed without mJA treatment in both control and transgenic lines, possibly as a result of growth in tissue culture plates, which comprised the environment where $\mathrm{BCN}$ infection assays were performed. Although the wildtype and $R h g 1^{+}$lines not treated with SA or mJA exhibited similar amounts of $P R 1$ or $P D F 1.2$, we observed significant differences in nematode resistance between the plant lines; therefore, it appears unlikely that chronic up-modulation of defenses indicated by $P R 1$ or PDF1.2 mRNA abundance caused the nematode resistance that was observed in Arabidopsis lines expressing Rhgl genes.

Our unanticipated identification of an Arabidopsis line that confers nematode resistance through high expression of only the Glyma.18G24400-encoded putative amino acid permease supports previous work indicating that $\alpha-\mathrm{SNAP}_{R h g 1}$ is not the only protein contributing to resistance at the Rhgl locus (Cook et al. 2012). This topic merits deeper analysis in future studies. We were also intrigued when observing increased resistance against root knot nematodes in the Arabidopsis line expressing all three Rhglencoded proteins, but not the line expressing only the Rhgl amino acid permease-like protein. Because chronic upregulation of canonical markers of defenses was not observed, it is possible that the Rhgl locus more directly interferes with general nematode parasitism, not just cyst nematode infection processes. However, in multiple studies of soybean resistance to $M$. incognita, the Rhgl locus has never been detected as making a contribution to soybean root knot nematode resistance (Kim et al. 2016). Although all three Rhgl genes have been demonstrated to be required for full resistance in soybean (Cook et al. 2012), the function of the encoded proteins may not be completely similar when ectopically expressed in heterologous plant species.

The mechanisms of resistance mediated by two of the three Rhgl genes remain poorly understood, but the mechanism of the Rhgl $\alpha$-SNAP has been partly elucidated. This gene confers resistance through the accumulation of a toxic version of a housekeeping gene in the complex and essential biotrophic interface, the nematodeinduced syncytium (Bayless et al. 2016). Overexpression of such a toxic gene in other plants could be a cause for concern regarding overall toxicity. The present study showed that, as in soybean, the native $\alpha$-SNAP proteins of Arabidopsis and potato can at least partially compensate for the inherent toxicity of the $\alpha-\mathrm{SNAP}_{R h g 1}$.

Although native $\alpha$-SNAP proteins can help compensate for the inherently toxic $\alpha-\mathrm{SNAP}_{\text {Rhgl }}$, there were still observable consequences of Rhgl expression in the transgenic lines. Rhglexpressing Arabidopsis root systems appeared relatively normal, but the main tap roots of young noninoculated Rhgl-expressing Arabidopsis plants did add less length over a 4-day period in both the single insertion line expressing all three $R h g l$ proteins and in the multiple insertion lines primarily expressing Glyma.18g24400. The Rhgl-expressing Arabidopsis roots were accessed at a similar rate by infective juveniles, suggesting that the resistance phenotype was not caused by a decrease in nematode penetration, but rather because of responses occurring after infection. This is consistent
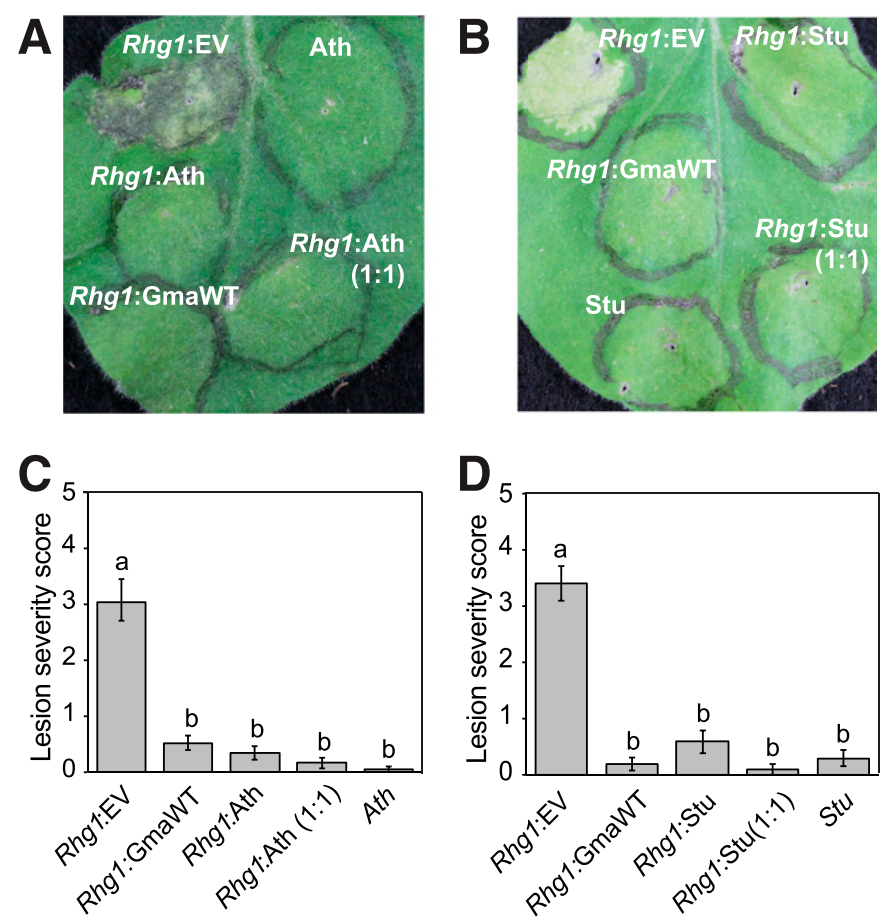

Fig. 5. Potato and Arabidopsis $\alpha$-SNAP proteins relieve cytotoxicity caused by soybean $\alpha-\mathrm{SNAP}_{R h g 1}$. Nicotiana benthamiana agro-infiltration $\alpha-\mathrm{SNAP}_{R h g 1}$ cytotoxicity assay of functional competition between wild-type $\alpha$-SNAPs and toxic $\alpha-\mathrm{SNAP}_{R h g 1}(R h g 1)$ is shown. Wild-types are from A, Arabidopsis (Ath; At3g56190) or B, potato (Stu; Sotub06g011010). Both panels also contain empty vector (EV) and wild-type soybean $\alpha$-SNAP (GmaWT; Glyma.18G022500) controls. All co-expression used a $3: 1$ ratio of the two Agrobacterium strains expressing the indicated proteins unless otherwise noted. Images were taken 8 to 9 days after infiltration, and treatment-blinded leaves were rated using a lesion severity scale of 0 to 5. C and D, Mean lesion severity ratings for leaves treated as in A or B, respectively. Error bars display SEM. Letters indicate significant differences (Wilcoxon rank-sum test, $P<$ 0.001). C, $n=17$. D, $n=12$. 
with soybean studies that showed that Rhgl blocks nematode development within roots rather than reducing the rate of initial root penetration (Chen et al. 2004). It was previously reported that certain Arabidopsis mutants with shorter root systems have increased susceptibility to BCN (Wubben et al. 2008). Hence, root length and susceptibility are not consistently correlated phenotypes.

A negative effect of Rhgl expression was also observed as a reduction in tuber biomass of $R h g 1$-expressing greenhouse-grown potatoes. The expression of Rhgl may interfere with general plant health, for example, by generic disruption of vesicle trafficking because of inefficient SNARE recycling by $\alpha$-SNAP and NSF (Bayless et al. 2016). However, general negative impacts on plant health have not been observed during decades of use of the PI88788 haplotype of $R h g l$ by soybean breeders who have routinely achieved high efficacy against SCN with no evidence of yield drag (Brucker et al. 2005). Targeted elevation of the Rhgl $\alpha$-SNAP in soybean syncytia is one apparent explanation for this, but the recent discovery of $\mathrm{NSF}_{\mathrm{RAN07}}$ offers another explanation (Bayless et al. 2018).

The negative phenotypic effect of Rhgl expression on potato tuber production might initially suggest that it is a less promising biotechnological approach to cyst nematode management in potato, sugar beet, or other crops. However, our research group discovered that soybean lines with SCN resistance-conferring Rhg ${ }^{+}$haplotypes also have a unique NSF protein variant, $\mathrm{NSF}_{\text {RAN07, }}$, because of an alternative allele of Glyma.07G195900. $\mathrm{NSF}_{\mathrm{RAN} 07}$ is always coinherited when a resistance-associated Rhgl locus is inherited, despite being encoded on a separate chromosome (Bayless et al. 2018). This NSF allele at least partially restores the $\alpha$-SNAP/NSF interaction that was reduced between wild-type NSF and $\alpha-\mathrm{SNAP}_{\text {Rhgl }}$. This suggested that soybeans have co-evolved $\mathrm{NSF}_{\mathrm{RAN07}}$ to overcome pleiotropic negative effects of Rhgl in other tissues or stages of plant development. In the future, cotransformation of Rhgl with the gene encoding $\mathrm{NSF}_{\text {RAN07 may }}$ improve the agronomic potential of Rhgl for engineering other plant species toward improved resistance to cyst nematodes.

Overall, our results suggested that $R h g l$ has evolved to interfere with a conserved cyst nematode infection process, and that soybeans have been able to adapt to the expression of this locus. Because of the role that Rhgl has been shown to have in interfering with vesicular trafficking, it can be postulated that cyst nematode parasitism relies on healthy host trafficking systems, which may be a target of conserved cyst nematode effectors. However, the other two genes of $R h g l$ are likely to interfere with other cyst nematode infection processes. Further studies of Rhgl resistance mechanisms and the associated mechanisms of cyst nematode parasitism will be useful to increase the understanding of how cyst nematodes cause disease and how we might thwart their efforts. Independent of future improvements in our understanding of resistance and virulence mechanisms, the present work demonstrated that the complex Rhgl resistance locus may have relevance beyond the management of $\mathrm{SCN}$ in soybean.

\section{ACKNOWLEDGMENTS}

We thank Adam Bayless for generating pCambia2300 three-gene Rhg 1 plasmids and for helpful discussions, and Jordyn Van, Amy Lirong Yan, and Patrick McMinn for assistance with the Arabidopsis work.

\section{LITERATURE CITED}

Allen, T.W., Bradley, C.A., Sisson, A.J., Byamukama, E., Chilvers, M.I., Coker, C.M., Collins, A.A., Damicone, J.P., Dorrance, A.E., Dufault, N.S., et al. 2017. Soybean yield loss estimates due to diseases in the United States and Ontario, Canada, from 2010 to 2014. Plant Health Prog. 18:19-27.

Bayless, A. M., Smith, J. M., Song, J., McMinn, P. H., Teillet, A., August, B. K., and Bent, A. F. 2016. Disease resistance through impairment of $\alpha$-SNAP-NSF interaction and vesicular trafficking by soybean Rhg 1. Proc. Natl. Acad. Sci. USA 113:E7375-E7382.
Bayless, A. M., Zapotocny, R. W., Grunwald, D. J., Amundson, K. K., Diers, B. W., and Bent, A. F. 2018. An atypical N-ethylmalemide sensitive factor enables the viability of nematode-resistant Rhgl soybeans. Proc. Natl. Acad. Sci. 115:E4512-E4521.

Boutrot, F., and Zipfel, C. 2017. Function, discovery, and exploitation of plant pattern recognition receptors for broad-spectrum disease resistance. Annu. Rev. Phytopathol. 55:257-286.

Brodie, B. B., and Mai, W. F. 1989. Control of the golden nematode in the United States. Annu. Rev. Phytopathol. 27:443-461.

Brucker, E., Niblack, T., Kopisch-Obuch, F. J., and Diers, B. W. 2005. The effect of on reproduction of Heterodera glycines in the field and greenhouse and associated effects on agronomic traits. Crop Sci. 45:1721-1727.

Bybd, D. W., Jr., Kirkpatrick, T., and Barker, K. R. 1983. An improved technique for clearing and staining plant tissues for detection of nematodes. J. Nematol. 15:142-143.

Cai, D. 1997. Positional cloning of a gene for nematode resistance in sugar beet. Science 275:832-834.

Chen, S., Li, Y., and Young, N.. 2004. Effect of the rhgl gene on penetration, development and reproduction of Heterodera glycines race 3. Nematology 6:729-736.

Chen, R., Li, H., Zhang, L., Zhang, J., Xiao, J., and Ye, Z. 2007. CaMi, a rootknot nematode resistance gene from hot pepper (Capsium annuum L.) confers nematode resistance in tomato. Plant Cell Rep. 26:895-905.

Chronis, D., Chen, S., Lang, P., Tran, T., Thurston, D., and Wang, X. 2014a. Potato transformation. Bio Protoc. 4:e1017.

Chronis, D., Chen, S., Lang, P., Tran, T., Thurston, D., and Wang, X. 2014b. In vitro nematode infection on potato plant. Bio Protoc. 4:e1016.

Clough, S. J., and Bent, A. F. 1998. Floral dip: a simplified method for Agrobacterium-mediated transformation of Arabidopsis thaliana. Plant J. 16:735-743.

Collinge, D. B., Jørgensen, H. J. L., Lund, O. S., and Lyngkjær, M. F. 2010. Engineering pathogen resistance in crop plants: Current trends and future prospects. Annu. Rev. Phytopathol. 48:269-291.

Cook, D. E., Bayless, A. M., Wang, K., Guo, X., Song, Q., Jiang, J., and Bent, A. F. 2014. Distinct copy number, coding sequence, and locus methylation patterns underlie Rhgl-mediated soybean resistance to soybean cyst nematode. Plant Physiol. 165:630-647.

Cook, D. E., Lee, T. G., Guo, X., Melito, S., Wang, K., Bayless, A. M., Wang, J., Hughes, T. J., Willis, D. K., Clemente, T. E., et al. 2012. Copy number variation of multiple genes at Rhgl mediates nematode resistance in soybean. Science 338:1206-1209.

Endo, B. Y. 1964. Penetration and development of Heterodera glycines in soybean roots and related anatomical changes. Phytopathology 54:79-88.

Evans, K., and Rowe, J. 1998. Distribution and economic importance. Pages 1-30 in: The Cyst Nematodes. S. B. Sharma, ed. Kluwer Academic Publishers, Dordrecht, Boston.

Finkers-Tomczak, A., Bakker, E., de Boer, J., van der Vossen, E., Achenbach, U., Golas, T., Suryaningrat, S., Smant, G., Bakker, J., and Goverse, A. 2011. Comparative sequence analysis of the potato cyst nematode resistance locus $H 1$ reveals a major lack of co-linearity between three haplotypes in potato (Solanum tuberosum sp.). Theor. Appl. Genet. 122:595-608.

Fridman, Y., Elkouby, L., Holland, N., Vragovi, K., Elbaum, R., and Savaldi-Goldstein, S. 2014. Root growth is modulated by differential hormonal sensitivity in neighboring cells. Genes Dev. 28:912-920.

Gardner, M., Heinz, R., Wang, J., and Mitchum, M. G. 2017. Genetics and adaptation of soybean cyst nematode to broad spectrum soybean resistance. G3 (Bethesda) 7:835-841.

Garner, C. M., Kim, S. H., Spears, B. J., and Gassmann, W. 2016. Express yourself: Transcriptional regulation of plant innate immunity. Semin. Cell Dev. Biol. 56:150-162.

Gebhardt, C. 2013. Bridging the gap between genome analysis and precision breeding in potato. Trends Genet. TIG 29:248-256.

Gibson, D. G., Young, L., Chuang, R.-Y., Venter, J. C., Hutchison, C. A., and Smith, H. O. 2009. Enzymatic assembly of DNA molecules up to several hundred kilobases. Nat. Methods 6:343-345.

Goggin, F. L., Jia, L., Shah, G., Hebert, S., Williamson, V. M., and Ullman, D. E. 2006. Heterologous expression of the Mi-1.2 gene from tomato confers resistance against nematodes but not aphids in eggplant. Mol. PlantMicrobe Interact. 19:383-388.

Guo, W., Zhang, F., Bao, A., You, Q., Li, Z., Chen, J., Cheng, Y., Zhao, W., Shen, X., Zhou, X., and Jiao, Y. 2019. The soybean Rhgl amino acid transporter gene alters glutamate homeostasis and jasmonic acid-induced resistance to soybean cyst nematode. Mol. Plant Pathol. 20:270-286.

Hamamouch, N., Li, C., Hewezi, T., Baum, T. J., Mitchum, M. G., Hussey, R. S., Vodkin, L. O., and Davis, E. L. 2012. The interaction of the novel $30 \mathrm{C} 02$ cyst nematode effector protein with a plant beta-1,3-endoglucanase may suppress host defense to promote parasitism. J. Exp. Bot. 63: 3683-3695. 
Hauer, M., Koch, H.-J., and Märländer, B. 2015. Water use efficiency of sugar beet cultivars (Beta vulgaris L.) susceptible, tolerant or resistant to Heterodera schachtii (Schmidt) in environments with contrasting infestation levels. Field Crops Res. 183:356-364.

Hernandez-Garcia, C. M., Bouchard, R. A., Rushton, P. J., Jones, M. L., Chen, X., Timko, M. P., and Finer, J. J. 2010. High level transgenic expression of soybean (Glycine max) GmERF and Gmubi gene promoters isolated by a novel promoter analysis pipeline. BMC Plant Biol. 10:237.

Jaouannet, M., Magliano, M., Arguel, M. J., Gourgues, M., Evangelisti, E., Abad, P., and Rosso, M. N. 2013. The root-knot nematode calreticulin MiCRT is a key effector in plant defense suppression. Mol. Plant-Microbe Interact. 26:97-105.

Kammerhofer, N., Radakovic, Z., Regis, J. M. A., Dobrev, P., Vankova, R., Grundler, F. M. W., Siddique, S., Hofmann, J., and Wieczorek, K. 2015. Role of stress-related hormones in plant defence during early infection of the cyst nematode Heterodera schachtii in Arabidopsis. New Phytol. 207: 778-789.

Kim, K. S., Vuong, T., Qiu, D., Robbins, R. T., Shannon, J. G., Li, Z., and Nguyen, H. T. 2016. Advancements in breeding, genetics, and genomics for resistance to three nematode species in soybean. Theor. Appl. Genet. 129: 2295-2311.

Klock, H. E., and Lesley, S. A. 2009. The polymerase incomplete primer extension (PIPE) method applied to high-throughput cloning and sitedirected mutagenesis. Pages 91-103 in: High Throughput Protein Expression and Purification. S. A.Doyle, ed. Humana Press, Totowa, NJ.

Kusch, S., and Panstruga, R. 2017. mlo-based resistance: An apparently universal "weapon" to defeat powdery mildew disease. Mol. Plant-Microbe Interact. 30:179-189.

Kyndt, T., Vieira, P., Gheysen, G., and de Almeida-Engler, J. 2013. Nematode feeding sites: Unique organs in plant roots. Planta 238:807-818.

Lee, T. G., Kumar, I., Diers, B. W., and Hudson, M. E. 2015. Evolution and selection of Rhg1, a copy-number variant nematode-resistance locus. Mol. Ecol. 24:1774-1791.

Liu, S., Kandoth, P. K., Lakhssassi, N., Kang, J., Colantonio, V., Heinz, R., Yeckel, G., Zhou, Z., Bekal, S., Dapprich, J., et al. 2017. The soybean GmSNAP18 gene underlies two types of resistance to soybean cyst nematode. Nat. Commun. 8:14822.

Livak, K. J., and Schmittgen, T. D. 2001. Analysis of relative gene expression data using real-time quantitative PCR and the 2(-Delta Delta C(T)) method. Methods 25:402-408.

Lu, S.-W., Tian, D., Borchardt-Wier, H. B., and Wang, X. 2008. Alternative splicing: A novel mechanism of regulation identified in the chorismate mutase gene of the potato cyst nematode Globodera rostochiensis. Mol. Biochem. Parasitol. 162:1-15.

McCarville, M. T., Marett, C. C., Mullaney, M. P., Gebhart, G. D., and Tylka, G. L. 2017. Increase in soybean cyst nematode virulence and reproduction on resistant soybean varieties in Iowa from 2001 to 2015 and the effects on soybean yields. Plant Health Prog. 18:146-155.

Meijering, E., Jacob, M., Sarria, J.-C. F., Steiner, P., Hirling, H., and Unser, M. 2004. Design and validation of a tool for neurite tracing and analysis in fluorescence microscopy images. Cytom. Part J. Int. Soc. Anal. Cytol. 58: 167-176.
Melito, S., Heuberger, A. L., Cook, D., Diers, B. W., MacGuidwin, A. E., and Bent, A. F. 2010. A nematode demographics assay in transgenic roots reveals no significant impacts of the Rhgl locus LRR-Kinase on soybean cyst nematode resistance. BMC Plant Biol. 10:104.

Minnis, S. T., Haydock, P. P. J., Ibrahim, S. K., Grove, I. G., Evans, K., and Russell, M. D. 2002. Potato cyst nematodes in England and WalesOccurrence and distribution. Ann. Appl. Biol. 140:187-195.

Narusaka, M., Kubo, Y., Hatakeyama, K., Imamura, J., Ezura, H., Nanasato, Y., Tabei, Y., Takano, Y., Shirasu, K., and Narusaka, Y. 2013. Interfamily transfer of dual NB-LRR genes confers resistance to multiple pathogens. PLoS One 8:e55954.

Niblack, T. L. 2005. Soybean cyst nematode management reconsidered. Plant Dis. 89:1020-1026.

Nicol, J. M., Turner, S. J., Coyne, D. L., den Nijs, L., Hockland, S., and Maafi, Z. T. 2011. Current nematode threats to world agriculture, Pages 21-43 in: Genomics and Molecular Genetics of Plant-Nematode Interactions. J. Jones, G. Gheysen, and C. Fenoll, eds. Springer, Netherlands, Dordrecht.

Plantard, O., Picard, D., Valette, S., Scurrah, M., Grenier, E., and Mugniéry, D. 2008. Origin and genetic diversity of Western European populations of the potato cyst nematode (Globodera pallida) inferred from mitochondrial sequences and microsatellite loci. Mol. Ecol. 17:2208-2218.

Siddique, S., and Grundler, F. M. W. 2015. Metabolism in nematode feeding sites, Pages 119-138 in: Plant Nematode Interactions-A View on Compatible Interrelationships, Edition: Advances in Botanical Research. C. Escobar and C. Fenoll, eds. Elsevier.

Sijmons, P. C., Grundler, F. M. W., Mende, N., Burrows, P. R., and Wyss, U. 1991. Arabidopsis thaliana as a new model host for plant-parasitic nematodes. Plant J. 1:245-254.

Sobczak, M., Avrova, A., Jupowicz, J., Phillips, M. S., Ernst, K., and Kumar, A. 2005. Characterization of susceptibility and resistance responses to potato cyst nematode (Globodera spp.) infection of tomato lines in the absence and presence of the broad-spectrum nematode resistance Hero gene. Mol. Plant-Microbe Interact. 18:158-168.

Turner, S., and Rowe, J. 2006. Cyst nematodes. Pages 91-122 in: Plant Nematology. R. N. Perry and M. Moens, eds. CABI, Wallingford, U.K.

Wubben, M. J., Su, H., Rodermel, S. R., and Baum, T. J. 2001. Susceptibility to the sugar beet cyst nematode is modulated by ethylene signal transduction in Arabidopsis thaliana. Mol. Plant-Microbe Interact. 14: 1206-1212.

Wubben, M. J. E., Jin, J., and Baum, T. J. 2008. Cyst nematode parasitism of Arabidopsis thaliana is inhibited by salicylic acid (SA) and elicits uncoupled SA-independent pathogenesis-related gene expression in roots. Mol. Plant-Microbe Interact. 21:424-432.

Zhang, C.-L., Xu, D.-C., Jiang, X.-C., Zhou, Y., Cui, J., Zhang, C.-X., Chen, D.-F., Fowler, M. R., Elliott, M. C., Scott, N. W., et al. 2008. Genetic approaches to sustainable pest management in sugar beet (Beta vulgaris). Ann. Appl. Biol. 152:143-156.

Zhang, Z. J., and Peck, S. C. 2011. Simplified enrichment of plasma membrane proteins for proteomic analyses in Arabidopsis thaliana. Proteomics 11:1780-1788 